\title{
Efficacy of selected herbs for their potential antioxidant activity in burfi, an Indian sweetmeat
}

\author{
Writdhama Prasad, Kaushik Khamrui, Gunvantsinh Rathod, Richa Badola and Hari Ram Gupta
}

Received: 02 May 2018 / Accepted: 20 December 2018 / Published online: 21 February 2019

(C) Indian Dairy Association (India) 2019

\begin{abstract}
Turmeric, ginger and cardamom were incorporated into burfi from $0.5-1.5 \%$ level and evaluated for anti-oxidative, instrumental color and sensorial attributes. Anti-oxidative activity was found to increase significantly $(\mathrm{p}<0.05)$ with increase in the level of herbs. Hunter colour values also changed significantly $(p<0.05)$ with herbs level. Increasing turmeric level increased $(\mathrm{p}<0.05)$ redness $\left(\mathrm{a}^{*}\right.$ value $)$ and yellowness $(\mathrm{b} *$ value, and cardamom decreased lightness ( $\mathrm{L}^{*}$ value). Addition of more than $0.5 \%$ turmeric, $1.0 \%$ ginger and $1.0 \%$ cardamom resulted in significant $(\mathrm{p}<0.05)$ decrease in sensory scores. These levels were considered optimum for incorporation into burfi. Highest anti-oxidative activity was observed with turmeric added samples followed by ginger and cardamom exhibited the least, but all the samples had significantly $(\mathrm{p}<0.05)$ higher activity than control and lower than BHA (200 ppm) added samples. Considering all the studied attributes, ginger $(1 \%)$ was found to be the most suitable herb for incorporation into burfi.
\end{abstract}

Keywords: Anti-oxidative activity, Instrumental color values, Sensory evaluation

Writdhama Prasad ( $\square$ )

Dairy Technology Division, ICAR-National Dairy Research Institute, Karnal-132001 (Haryana), India

Ph: 0184-2259247; Fax: 0184-2250042

E-mail: writdhama_3993@rediffmail.com

Kaushik Khamrui, Gunvantsinh Rathod, Richa Badola and Hari Ram Gupta

Dairy Technology Division, ICAR-National Dairy Research Institute, Karnal-132001 (Haryana), India

\section{Introduction}

Traditional Indian dairy products have a huge demand, while their domestic markets are well established, global market appears as silver lining for large Indian diaspora living abroad. However, in order to compete and to cope up with the rising functional food market, improvement in functionality and novelty in traditional dairy product is immensely required. Burfi, a khoa based sweetmeat, rich in essential nutrients, contains high amount of free moisture and around $60 \%$ its fat remains in free form (Palit and $\mathrm{Pal}, 2005$ ). Although presence of free fat is essential for typical flavour as well as shiny appearance of burfi, but it also renders burfi susceptible to oxidative degradation (Palit and Pal, 2005). The author also reported lipid oxidation in plain burfi led to fatty acids degradation which reduced its sensory attributes to unacceptable levels. Besides decreasing products' acceptability, oxidized fat has also been associated with various chronic diseases. Patel et al. (2013) reported lipid oxidation can adversely affect the nutritional value, sensory quality, and shelf life of foods.

As per reported studies, lipid oxidation can be omitted only if any antioxidant is present in system. Synthetic antioxidant are allowed by law but their practice are discouraged due to their related health hazards. Natural antioxidants can be a better option to overcome the oxidation (Hussain et al., 2015). Number of studies on anti-oxidant activity of these herbs and their effect on food products has been reported till date. Increase in antioxidative activity in goat milk yoghurt has been reported upon addition of ginger into it (Srivastava et al., 2015). Ismail (2005) reported anti-oxidant effects of ginger in Mackerel patties during refrigerated storage. Buch et al. (2014) reported increased keeping quality of paneer upon incorporation of turmeric into it. Prasad et al. (2018) reported incorporation of herbal extracts increased the anti-oxidative potential in burfi.

These documented studies suggest utilization of herbs in various food products but no documented study was reported regarding use of herbs in to khoa so far. Incorporation of herbs in burfi can provide opportunities to enhance the keeping quality and functional attributes. The present study was undertaken to investigate the effect of incorporation of turmeric, ginger and cardamom on various physicochemical and sensorial attributes 
of burfi. Project findings will be helpful in utilization of herbs in traditional dairy products besides increasing their functionality.

\section{Materials and methods}

\section{Ingredients and chemicals}

Fresh buffalo milk was procured from Experimental Dairy of ICARNational Dairy Research Institute, Karnal, India. Spray dried skimmed milk powder, procured from the M/s Modern Dairies Ltd. (Karnal), was used for standardization of milk. Turmeric, ginger and cardamom was procured from local market. All the chemicals used in the present study were purchased from $\mathrm{M} / \mathrm{s}$ Hi-Media (P) Ltd., (Mumbai).

\section{Preparation of burfi}

Burfi was prepared by atmospheric desiccation of standardized milk using the standard batch method proposed by Aneja et al. (2002). Ground sugar (@30\% of khoa), mixed with individual herbs ( 0.5 to $1.5 \%$ of $k h o a$ ), was added during the final stages of preparation. Level of the individual herb was optimized based upon sensory attributes. Different herbs were compared with each other at their optimum level and with control and BHA (200 ppm of khoa) added sample.

\section{Determination of total phenolic content and free radical scavenging activity}

DPPH (2, 2 Diphenyl-1-picryl hydrazyl) and ABTS [2, 2'-azinobis (3 ethyl benzothiazoline)-6-sulfonic acid] free radical scavenging activity in burfi was evaluated by the method of Prasad et al. (2017a) and calculated using the following formula.

$$
\% \text { Free radical scavenging activity }=\frac{(\text { Control Absorbance }- \text { Sample absorbance })^{* 100}}{\text { Blank absorbance }}
$$

Total phenolic content of burfi was analyzed by Folin Ciocalteu's method provided by Zhang et al. (2006) with minor modifications. Twenty microlitre of appropriately diluted sample was taken in a test tube. $100 \mu \mathrm{L}$ of diluted Folin-Ciocalteu's reagent was mixed to it. After 3 minutes, $80 \mu \mathrm{L}$ of $20 \%$ sodium carbonate solution was added. For blank preparation, $20 \mu \mathrm{L}$ of distilled water was taken instead of sample. The absorbance of the samples was measured against blank at $730 \mathrm{~nm}$. Total phenol content of sample was calculated using equation of standard curve and the results are expressed as $\mu \mathrm{g}$ gallic acid equivalent (GAE) per gram of burfi.

\section{Determination of Hunter color values}

Colour measurements were conducted using Color Flex (M/s Hunter Associates Laboratory, Inc., Reston VA, USA) color measurement system equipped with dual beam xenon flash lamp and universal software.

\section{Sensory evaluation}

Herbal burfi samples prepared during the course of investigation was sensorily evaluated using a 9-point hedonic scale by a panel of trained judges selected from Faculty of Dairy Technology Division.

\section{Statistical analysis}

Data obtained from various experiments was recorded as mean \pm standard error (SE) and were statistically analyzed using one way analysis of variance (ANOVA) followed by Tukey'b comparison test to establish the significance of differences among the mean values at $5 \%$ level of significance $(\mathrm{p}<0.05)$ using SPSS software of M/s IBM Corporation.

\section{Results and discussion}

\section{Effect of incorporation of different levels of herbs on sensory attributes of $b u r f i$}

\section{Changes in flavour scores}

Flavour is one of the important parameters in acceptability of the dairy product. Flavour score of burfi incorporated with turmeric, ginger and cardamom were ranged from 7.05 to $5.92,7.33$ to 6.72 and 7.50 to 6.88 respectively, upon increasing level of respective herb from 0.5 to $1.5 \%$. All the three herbs were found to significantly $(\mathrm{p}<0.05)$ affect the flavour score of burfi. In addition, it was also observed that all the samples were acceptable to the panellists, but to different extent for the individual herb. For turmeric, flavour scores progressively decreased with increasing turmeric levels. But for ginger and cardamom, the scores first remained similar at lower levels (up to $1 \%$ ) and upon further increasing their level, the scores followed similar trend as observed in the case of turmeric. The decrease in flavour scores with increasing herb incorporation level could be attributed to increase in the level of polyphenolic compounds. Bitterness and astringency are the major flavours associated with polyphenols (Lesschaeve and Noble, 2005), which might be responsible for lowering the flavour scores. Le Bourvellec and Renard (2012) reported polyphenols contributes to astringency and bitter taste. Biologically active constituents present in turmeric, ginger and cardamom are described in the later section. The presence of more than desired level of these phenolic compounds could have resulted in reduced flavour scores with increasing levels of herbs.

\section{Changes in colour and appearance scores}

Colour and appearance of any product decides its degree of liking and has a crucial role to play in its acceptability. Experimental data indicated that colour and appearance scores of turmeric, ginger and cardamom incorporated burfi ranged from 7.10 to 6.11, 7.45 to 6.30 and 7.40 to 6.81 , respectively upon increasing level of the individual herb. Significant $(\mathrm{p}<0.05)$ effect of turmeric and 
cardamom incorporation was found on colour and appearance attribute of herbal burfi, which could be due to the pigments imparted by these herbs. The yellow color of turmeric and ginger is due to the presence of curcuminoids (Anandaraj \& Sudharshan, 2011), while Parthasarathy et al. (2008) reported cyanidin 3-glucoside as the prime pigment in cardamom.

\section{Changes in body and texture scores}

Body and texture is a critical factor which plays a major role in acceptability of burfi. Upon increasing level of herbs from 0.5 to
$1.5 \%$, body and texture scores of turmeric incorporated burfi decreased $(p>0.05)$ from 7.11 to 6.80 , similarly significant $(p<0.05)$ decrease from 7.51 to 6.95 upon cardamom incorporation, but ginger incorporation into burfi led to significantly not different $(p>0.05)$ decrease in scores from 7.25 to 7.01. Effect herb incorporation on body and texture scores of burfi could have been due to the components present in these herbs, viz., fibers, polyphenols, etc. Balestra et al. (2011) reported an increase in hardness of cake beyond 4\% ginger incorporation, which the authors attributed to proteins, carbohydrates and minor constituents of ginger such as gingerol.

Table 1 Effect of addition of different levels (\% of khoa) of raw herb on sensory attributes of burfi

\begin{tabular}{llll}
\hline Parameters (scores) & 0.5 & 1.0 & 1.5 \\
\hline & & Turmeric & \\
Flavor & $7.05 \pm 0.25^{\mathrm{a}}$ & $6.52 \pm 0.17^{\mathrm{b}}$ & $5.92 \pm 0.20^{\mathrm{c}}$ \\
Color \& Appearance & $7.10 \pm 0.30^{\mathrm{a}}$ & $6.94 \pm 0.27^{\mathrm{a}}$ & $6.11 \pm 0.19^{\mathrm{b}}$ \\
Texture & $7.11 \pm 0.34^{\mathrm{a}}$ & $7.13 \pm 0.26^{\mathrm{a}}$ & $6.80 \pm 0.31^{\mathrm{a}}$ \\
Overall Acceptability & $7.05 \pm 0.25^{\mathrm{a}}$ & $6.60 \pm 0.20^{\mathrm{b}}$ & $5.99 \pm 0.23^{\mathrm{c}}$ \\
& & Ginger & $6.72 \pm 0.31^{\mathrm{b}}$ \\
Flavor & $7.33 \pm 0.29^{\mathrm{a}}$ & $7.29 \pm 0.20^{\mathrm{a}}$ & $6.30 \pm 0.22^{\mathrm{b}}$ \\
Color \& Appearance & $7.45 \pm 0.17^{\mathrm{a}}$ & $7.31 \pm 0.32^{\mathrm{a}}$ & $7.01 \pm 0.21^{\mathrm{a}}$ \\
Texture & $7.18 \pm 0.28^{\mathrm{a}}$ & $7.25 \pm 0.25^{\mathrm{a}}$ & $6.75 \pm 0.29^{\mathrm{b}}$ \\
Overall Acceptability & $7.30 \pm 0.23^{\mathrm{a}}$ & $7.26 \pm 0.21^{\mathrm{a}}$ & \\
& & $C a r d a m o m$ & $7.50 \pm 0.29^{\mathrm{a}}$ \\
Flavor & $7.42 \pm 0.23^{\mathrm{a}}$ & $7.28 \pm 0.25^{\mathrm{a}}$ & $6.88 \pm 0.24^{\mathrm{b}}$ \\
Color \& Appearance & $7.40 \pm 0.30^{\mathrm{a}}$ & $7.26 \pm 0.27^{\mathrm{b}}$ & $6.81 \pm 0.21^{\mathrm{b}}$ \\
Texture & $7.51 \pm 0.28^{\mathrm{a}}$ & $7.39 \pm 0.25^{\mathrm{a}}$ & $6.95 \pm 0.22^{\mathrm{c}}$ \\
Overall Acceptability & $7.48 \pm 0.55^{\mathrm{a}}$ & & $6.90 \pm 0.20^{\mathrm{b}}$ \\
\hline
\end{tabular}

Values are mean \pm standard deviation $(n=3)$

a,b,c,d,e: Means with different superscripts within a row differ significantly $(\mathrm{P}<0.05)$

Table 2 Effect of addition of different levels of raw herb (\% of khoa) on anti-oxidant activity of burfi

\begin{tabular}{|c|c|c|c|}
\hline Parameters & 0.5 & 1.0 & 1.5 \\
\hline & & Turmeric & \\
\hline TPC ( $\mu \mathrm{gGAE} / \mathrm{g})$ & $0.588 \pm 0.055^{\mathrm{a}}$ & $0.718 \pm 0.035^{\mathrm{b}}$ & $0.870 \pm 0.049^{c}$ \\
\hline \multirow[t]{2}{*}{ DPPH activity\# } & $10.16 \pm 0.53^{a}$ & $19.74 \pm 0.48^{\mathrm{b}}$ & $25.63 \pm 0.75^{\mathrm{c}}$ \\
\hline & & Ginger & \\
\hline TPC $(\mu \mathrm{gGAE} / \mathrm{g})$ & $0.510 \pm 0.043^{\mathrm{a}}$ & $0.652 \pm 0.063^{b}$ & $0.776 \pm 0.066^{\mathrm{c}}$ \\
\hline \multirow[t]{2}{*}{ DPPH activity\# } & $6.12 \pm 0.72^{\mathrm{a}}$ & $7.85 \pm 0.41^{\mathrm{b}}$ & $8.54 \pm 0.66^{c}$ \\
\hline & & Cardamom & \\
\hline TPC ( $\mu \mathrm{gGAE} / \mathrm{g})$ & $0.518 \pm 0.041^{\mathrm{a}}$ & $0.547 \pm 0.071^{\mathrm{b}}$ & $0.611 \pm 0.043^{c}$ \\
\hline ABTS activity\# & $11.05 \pm 0.61^{\mathrm{a}}$ & $11.83 \pm 0.49^{\mathrm{b}}$ & $12.87 \pm 0.79^{c}$ \\
\hline DPPH activity\# & $4.89 \pm 0.40^{\mathrm{a}}$ & $6.24 \pm 0.63^{\mathrm{b}}$ & $7.64 \pm 1.05^{\mathrm{c}}$ \\
\hline
\end{tabular}

(ABTS, DPPH activity) $=\%$ inhibition;

Values are mean \pm standard deviation $(n=3)$ a,b,c,d,e: Means with different superscripts within a row differ significantly $(\mathrm{P}<0.05)$ 
Fig 1. Sensory attributes of different burfi samples

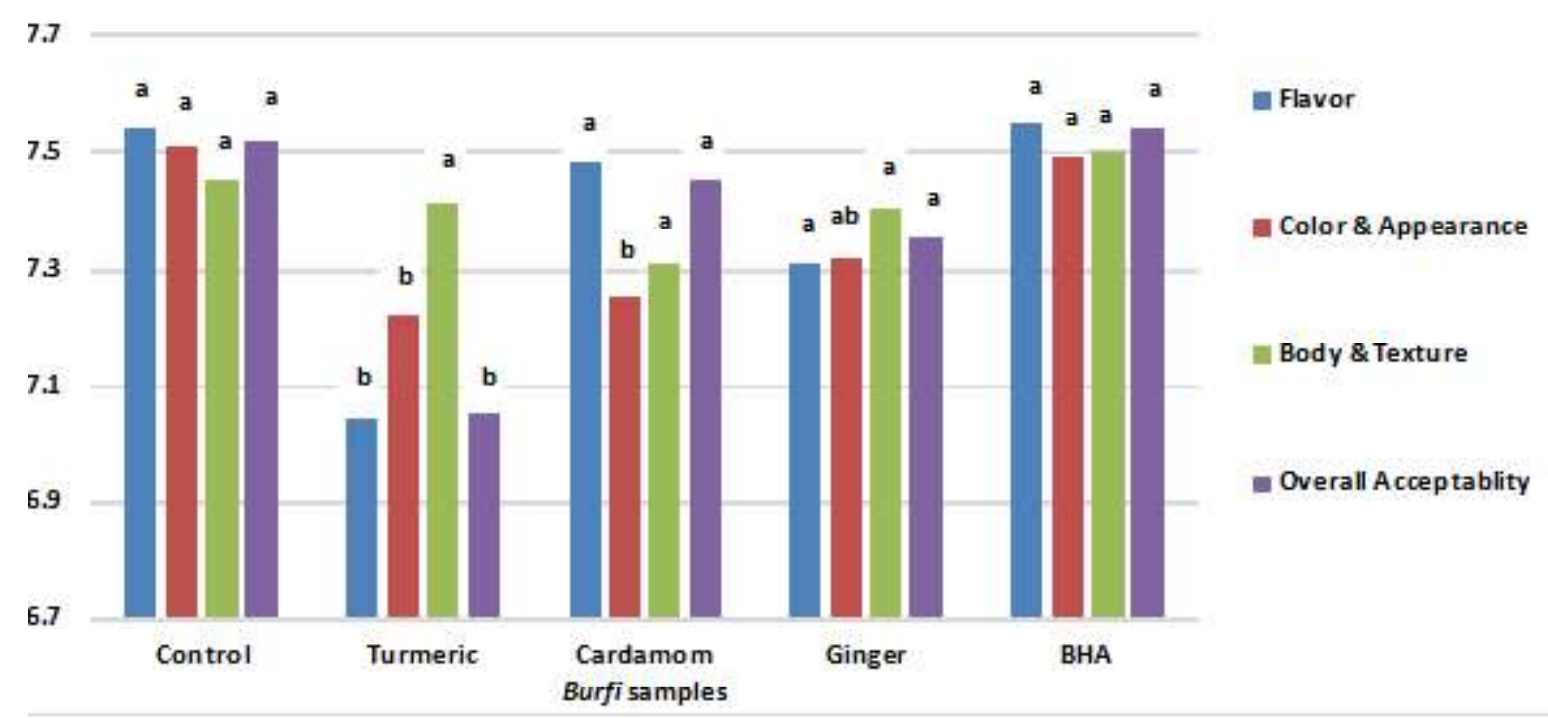

Values are mean $(\mathrm{n}=3)$

a,b,c,d,e, : Means with different superscripts within same parameter differ significantly $(\mathrm{P}<0.05)$

Table 3 Anti-oxidant activity in different burfi samples

\begin{tabular}{|c|c|c|c|c|c|}
\hline \multirow[t]{2}{*}{ Parameters } & \multirow[t]{2}{*}{ Control } & \multicolumn{3}{|c|}{ Herbal Burfi } & \multirow[t]{2}{*}{ BHA } \\
\hline & & Turmeric & Cardamom & Ginger & \\
\hline ТPC $(\mu \mathrm{gGAE} / \mathrm{g})$ & $0.408 \pm 0.061^{\mathrm{a}}$ & $0.591 \pm 0.057^{\mathrm{b}}$ & $0.552 \pm 0.050^{\mathrm{b}}$ & $0.643 \pm 0.059^{\mathrm{c}}$ & - \\
\hline ABTS activity\# & $10.83 \pm 0.21^{\mathrm{a}}$ & $31.05 \pm 0.42^{b}$ & $11.87 \pm 0.88^{\mathrm{c}}$ & $16.98 \pm 0.31^{\mathrm{d}}$ & $98.17 \pm 0.28^{\mathrm{e}}$ \\
\hline DPPH activity\# & $4.33 \pm 0.41^{\mathrm{a}}$ & $10.95 \pm 0.40^{\mathrm{b}}$ & $5.90 \pm 0.53^{\mathrm{c}}$ & $7.63 \pm 0.28^{\mathrm{d}}$ & $99.10+0.15^{\mathrm{e}}$ \\
\hline
\end{tabular}

\# (ABTS, DPPH activity) $=\%$ inhibition

Values are mean \pm standard deviation $(\mathrm{n}=3)^{\mathrm{a}, \mathrm{b}, \mathrm{c}, \mathrm{d}, \mathrm{e}, \text { }}$ : Means with different superscripts within a row differ significantly $(\mathrm{P}<0.05)$

Table 4 Effect of addition of different levels of herb (\% of $k h o a)$ on hunter color values of burfi

\begin{tabular}{lllc}
\hline Parameters & $0.5 \%$ & $1.0 \%$ & $1.5 \%$ \\
\hline $\mathrm{L}^{*}$ value & $65.99 \pm 0.83^{\mathrm{a}}$ & Turmeric & $62.50 \pm 1.03^{\mathrm{b}}$ \\
$\mathrm{a}^{*}$ value & $2.54 \pm 0.65^{\mathrm{a}}$ & $64.55 \pm 1.05^{\mathrm{a}}$ & $5.47 \pm 0.44^{\mathrm{b}}$ \\
$\mathrm{b}^{*}$ value & $32.03 \pm 1.09^{\mathrm{a}}$ & $4.10 \pm 1.06^{\mathrm{a}}$ & $47.16 \pm 1.3^{\mathrm{c}}$ \\
& & $39.52 \pm 1.14^{\mathrm{b}}$ & \\
$\mathrm{L}^{*}$ value & $67.54 \pm 0.53^{\mathrm{a}}$ & Ginger & $64.28 \pm 1.16^{\mathrm{b}}$ \\
$\mathrm{a}^{*}$ value & $2.18 \pm 0.48^{\mathrm{a}}$ & $66.89 \pm 0.89^{\mathrm{a}}$ & $4.37 \pm 0.61^{\mathrm{c}}$ \\
$\mathrm{b}^{*}$ value & $27.00 \pm 0.43^{\mathrm{a}}$ & $3.55 \pm 0.50^{\mathrm{b}}$ & $31.25 \pm 0.84^{\mathrm{c}}$ \\
& & $30.40 \pm 1.02^{\mathrm{b}}$ & \\
$\mathrm{L}^{*}$ value & $63.40 \pm 1.06^{\mathrm{a}}$ & Cardamom & $48.15 \pm 1.66^{\mathrm{c}}$ \\
$\mathrm{a}^{*}$ value & $2.07 \pm 0.81^{\mathrm{a}}$ & $54.96 \pm 2.41^{\mathrm{b}}$ & $3.96 \pm 0.45^{\mathrm{b}}$ \\
$\mathrm{b}^{*}$ value & $23.10 \pm 0.78^{\mathrm{a}}$ & $3.17 \pm 0.96^{\mathrm{ab}}$ & $25.18 \pm 0.63^{\mathrm{b}}$ \\
\hline
\end{tabular}

Values are mean \pm standard deviation $(\mathrm{n}=3)$

a,b,c,de: : Means with different superscripts within a row differ significantly $(\mathrm{P}<0.05)$

Changes in overall acceptability scores
Overall acceptability includes each and every attribute of the product, inclusive of those which are not provided in the score card. Reported score for overall acceptability of burfi changed 
significantly $(\mathrm{p}<0.05)$ upon herb incorporation and were found in the range from 5.99 to 7.05 for turmeric, 6.75 to 7.30 for ginger and 6.90 to 7.48 for cardamom, with increasing herb level from 0.5 to $1.5 \%$, respective (Table 1 ). The highest level of individual herb incorporation was selected based upon overall acceptability scores, i.e., the herb level after which overall acceptability scores decreased significantly $(\mathrm{p}<0.05)$, which were $0.5 \%$ for turmeric, $1 \%$ for ginger and cardamom.

Results obtained for sensory attributes of burfi added with different herbs at their highest acceptable level, control and BHA is presented in Figure 1. Flavour score for turmeric added burfi was $6.95,7.31$ for ginger and 7.47 for cardamom. Colour and appearance scores were $7.25,7.28$ and 7.32 for turmeric, ginger and cardamom added samples, and body and textural scores were 7.40, 7.31 and 7.40, respectively. Overall acceptability scores were $7.05,7.37$ and 7.45 for turmeric, ginger and cardamom added burfi samples, respectively. Sample added with turmeric was found to have significantly lower $(\mathrm{p}<0.05)$ sensory rating as compared to other herbs, control and BHA added samples.

\section{Effect of incorporation of different levels of herbs on anti-oxidant activity of burfi}

Anti-oxidant activities of different burfi samples were determined in terms free radical scavenging capacity (ABTS and DPPH) and TPC. Free radical (ABTS and DPPH) reducing capacity of turmeric incorporated burfi increased from $30.98 \%$ to $76.02 \%$ and $10.16 \%$ to $25.63 \%$, respectively. Also, TPC of burfi was found to increase from 0.588 to $0.870(\mu \mathrm{gGAE} / \mathrm{g})$ upon increasing turmeric levels from $0.5 \%$ to $1.5 \%$. Similarly, ginger incorporation from $0.5 \%$ to $1.5 \%$ led to increase in TPC from 0.510 to $0.776(\mu \mathrm{gGAE} / \mathrm{g})$ and free radical (ABTS and DPPH) reducing activity increased from 12.30 to $19.28 \%$ and 6.12 to $8.54 \%$, respectively. And, TPC increased from 0.518 to 0.611 ( $\mu \mathrm{gGAE} / \mathrm{g})$, while ABTS and DPPH free radical reducing activity increased from 11.05 to $12.87 \%$ and 4.89 to $7.64 \%$ upon increasing level of cardamom. Among these three herbs at similar level, turmeric was found to possess highest anti-oxidant activity followed by ginger and cardamom exhibited the least (Table 2). Also, increasing the concentration of herbs tended to increase anti-oxidant activity of burfi significantly $(\mathrm{p}<0.05)$.

Herbs are known to possess a wide variety of active phenolic compounds. Many reports emphasize direct relationship between phenolic content and anti-oxidant activity (Hussain et al., 2015) which has been attributed to the presence of hydroxyl units in their chemical structure (Shahidi, 2000). Curcumin is reported as principal polyphenolic compound in turmeric and, 6-gingerol and shagols in ginger (Singh et al., 2008). Likewise, 1,8-cineol and áterpineol acetate were found in cardamom (Savan et al., 2013). Similar results are reported by Prasad et al., (2017b)
Anti-oxidative activity of different herbs at their highest level of acceptance viz., $0.5 \%$ turmeric, $1.0 \%$ ginger and cardamom, and control and BHA added burfi is presented in Table 3. DPPH free radical scavenging capacity of burfi incorporated with turmeric was $10.95 \%, 5.90 \%$ with cardamom and $7.63 \%$ with ginger; while ABTS free radical reducing capacity of burfi incorporated with turmeric, ginger and cardamom were $31.05 \%, 11.87 \%$ and $16.98 \%$, respectively. TPC of burfi incorporated with turmeric was 0.591 (igGAE/g), 0.552 (igGAE/g) with cardamom and 0.643 (igGAE/g) with ginger. Upon comparison of different herbs, turmeric was found to have highest anti-oxidant activity followed by ginger and the least was obtained for cardamom, but all these herbal burfi samples had anti-oxidant activity lower $(\mathrm{p}<0.05)$ than that of synthetic anti-oxidant (BHA) added burfi and higher $(\mathrm{p}<0.05)$ than that of control burfi.

\section{Effect of incorporation of different levels of herbs on Hunter colour values of burfi}

Burfi incorporated with different herb at the level from 0.5 to $1.5 \%$ was evaluated for its instrumental colour parameters viz., lightness, yellowness, redness. Lightness ( $\mathrm{L}^{*}$ ) value of burfi decreased from 65.99 to 62.50 , whereas redness $\left(a^{*}\right)$ value increased from 3.54 to 5.47 and yellowness $\left(b^{*}\right)$ value increased from 32.03 to 47.16 upon increasing turmeric levels from 0.5 to $1.5 \%$ in burfi. On similar lines, ginger incorporation from 0.5 to $1.5 \%$ into burfi led to decrease in lightness $\left(\mathrm{L}^{*}\right)$ value from 67.54 to 64.28 , redness $\left(\mathrm{a}^{*}\right)$ value increased from 2.18 to 5.29 and yellowness $\left(b^{*}\right)$ value increased from 27.00 to 31.25 . Cardamom also led to similar changes in Hunter colour values but to a different extent. Lightness $\left(\mathrm{L}^{*}\right)$ value decreased from 63.40 to 48.15 , redness $\left(\mathrm{a}^{*}\right)$ value increased from 2.07 to 5.16 and yellowness $\left(b^{*}\right)$ value increased from 23.10 to 25.18 upon increasing concentration 0.5 to $1.5 \%$ (Table 4 ). The compounds responsible for these colours in burfi are already discussed in section 3.1.

\section{Conclusions}

Sensorial and physicochemical analysis of experimental burfi incorporated with different level of herb showed that increasing the level of herb incorporation increased the anti-oxidant capacity of burfi with concomitant changes in instrumental Hunter colour values of burfi. Upon comparing sensorial attributes, the scores of burfi decreased upon increasing turmeric level progressively, while with ginger and cardamom the scores first remained similar at lower concentration of herb, but further increase in herb level decreased the scores significantly $(p<0.05)$. Consumer acceptability is the utmost important factor for successful commercialization of any product in the market. The level of individual herb at which highest, not significant difference ( $p>0.05$ ) scores were obtained viz., $0.5 \%$ for turmeric, $1.0 \%$ for ginger and $1.0 \%$ for cardamom, were found suitable for incorporation into burfi. At these levels, although the antioxidative activity in burfi was higher than that from control burfi 
but lower than BHA added burfi. Among the three herbs, ginger and cardamom were found to be sensorially more acceptable than turmeric, and among these two, ginger was found to have high anti-oxidative activity. Based upon these results, ginger seems to be the most potential herb for incorporation into burfi in order to have highest anti-oxidative activity without compromising sensorial attributes.

\section{Acknowledgements}

Director, ICAR-NDRI (Karnal) is duly acknowledged for providing research facilities.

\section{References}

Anandaraj M, Sudharshan MR (2011) Cardamom, ginger and turmeric. Encyclopedia of Life Support Systems (EOLSS)-Soils, Plant Growth and Crop Production. EOLSS Publishers, Oxford, UK

Aneja RP, Mathur BN, Chandan RC, Banerjee AK (2002) Technology of Indian Milk Products. pp. 122-124, New Delhi: A Dairy India Publication

Balestra F, Cocci E, Pinnavaia G, Romani S (2011) Evaluation of antioxidant, rheological and sensorial properties of wheat flour dough and bread containing ginger powder. LWT-Food Sci Technol 44(3): 700-705

Buch S, Pinto S, Aparnathi KD (2014). Evaluation of efficacy of turmeric as a preservative in paneer. J Food Sci Technol 51(11): 3226-3234

Hussain SA, Panjagari NR, Singh RRB, Patil GR (2015) Potential herbs and herbal nutraceuticals: food applications and their interactions with food components. Crit Rev Food Sci Nutr 55(1): 94-122

Ismail N (2005) Antioxidative activity of ginger and coriander in cooked patties of mackerel (Scomber Scombrus) during storage. Sci Letters 2(1): 71-77

Le Bourvellec C, Renard, CMGC (2012) Interactions between polyphenols and macromolecules: quantification methods and mechanisms. Crit Rev Food Sci Nutr 52(3): 213-248
Lesschaeve I, Noble AC (2005) Polyphenols: factors influencing their sensory properties and their effects on food and beverage preferences. Am J Clin Nutr 81(1): 330S-335S

Palit C, Pal D (2005) Studies on mechanized production and shelf life extension of burfi. Indian J Dairy Sci 58(1): 12-16

Parthasarathy VA, Chempakam B, Zachariah TJ (2008) Chemistry of spices. Cabi. dx.doi.org/10.1079\%2F9781845934057.0000

Patel S, Shende S, Arora S, Singh AK (2013) An assessment of the antioxidant potential of coriander extracts in ghee when stored at high temperature and during deep fat frying. Int J Dairy Technol 66(2): 207-213

Prasad W, Khamrui K, Mandal S, Badola R (2017a) Anti-oxidative, physicochemical and sensory attributes of burfi affected by incorporation of different herbs and its comparison with synthetic anti-oxidant (BHA). J Food Sci Technol 54(12):3802-3809

Prasad W, Khamrui K, Sheshgiri S (2017b) Effect of Packaging Materials and Essential Oils on the Storage Stability of Burfi, a Dairy Dessert. J Pack Technol Res 1(3): 181-192

Prasad W, Khamrui K, Mandal S, Badola R, Sandhya S, Gupta HR (2018) Effect of incorporation of herbal essential oil on anti-oxidative, instrumental color and sensorial attributes of burfi. Indian Journal of Dairy Science. 71(2) : 156-161

Savan EK, Kucukbay FZ (2013) Essential oil composition of Elettaria cardamomum Maton. J Applied Biol Sci 7(3): 42-44

Shahidi F (2000). Antioxidants in food and food antioxidants. Mol Nutr Food Res 44(3): 158-163

Singh G, Kapoor IPS, Singh P, de Heluani CS, De Lampasona MP, Catalan CA (2008) Chemistry, antioxidant and antimicrobial investigations on essential oil and oleoresins of Zingiber officinale. Food and Chem Toxicol 46(10): 3295-3302

Srivastava P, Prasad SG, Sukla S (2015). Quality Evaluation of Functional Yoghurt Prepared from Different Milks. Trends Biosci 8(20): 56405644

Zhang Q, Zhang J, Shen J, Silva A, Dennis DA, Barrow CJ (2006) A simple 96-well microplate method for estimation of total polyphenol content in seaweeds. In: Eighteenth International Seaweed Symposium, Springer Netherlands, pp: 219-224 